\title{
Automated State-Survey System for Monitoring Salt Damages on Plastered Wall Surfaces
}

\author{
István Vidovszky ${ }^{1}$ and Farkas Pintér ${ }^{2}$
}

1 Budapest University of Technology and Economics, Budapest, Hungary

2 Scientific Laboratory, Federal Monuments Authority Austria, Vienna, Austria

\begin{abstract}
Salt damage is a common problem at many heritage sites and historical buildings. The accumulated salt can aggravate moisture problems, cause inconveniences in use, and physical decay of the structures, most commonly the damage of the plaster layers. Internet of things(loT-s) are becoming part of our advanced, contemporary toolset, which in case of proper establishment and settings enables us to collect data of the investigated facilities continuously, without a regular professional presence on site. In this research, an attempt has been made for continuous monitoring by the mean of a custom-designed single-board computer-based automatic survey station. The system records environmental (i.e., temperature, relative humidity) and visual data that enables state recording on a regular base in order to monitor historic buildings for preservation purposes.
\end{abstract}

(C) 2020 The Authors. Published by Budapest University of Technology and Economics \& Diamond Congress Ltd Peer-review under responsibility of the Scientific Committee of the Creative Construction Conference 2020.

Keywords: state survey, automated diagnostic system, surface condition monitoring, building health monitoring loT

\section{Introduction}

\subsection{Salt problems in historic buildings}

Problems caused by moisture and salt are common at heritage sites and monuments. There are several reasons behind the appearance of damaging salts in structures, which issues have been discussed by many authors. [e.g. 1-4] Salt problems can be triggered by the missing or inconvenient damp proofing, the damage of water or wastewater pipes, de-icing activities, inappropriate use of building materials, etc. In some cases, even by the storing and preservation of historic artifacts in the museums can cause salt problems. [5-6]

Because of the numerous factors, sometimes it can be a challenge to reveal the exact source of the appearing salt and moisture or to answer the question when and at what climatic conditions the salt damage occurs. For a more profound investigation of the background of these problems, we need to improve our toolsets used for monitoring historic buildings.

Some previous research aimed to have a proper system for the diagnostics and the monitoring of the state of historic sites [1, 7-8]. Recently, the automation of some aspects of the monitoring has also been tested [9-12]. 


\subsection{The goals of this study}

In this research, an attempt has been made to monitor the behavior of salts (i.e. appearance of efflorescence) on a wall surface without continuous human presence. The solution could be an loT-based automated inspection unit that later, according to our future development plans, can be part of a system for the regular remote monitoring of historic sites and building stocks.

The developed and demonstrated loT is responsible for taking digital images and detect the temperature and relative humidity repeatedly and automatically in previously defined time intervals, replacing the continuous human presence on the site. It enables us to collect data and to analyze the surface state continuously.

\section{Research method}

For the purposes of the research, a test surface was produced, that was investigated with a uniquely designed automated survey unit.

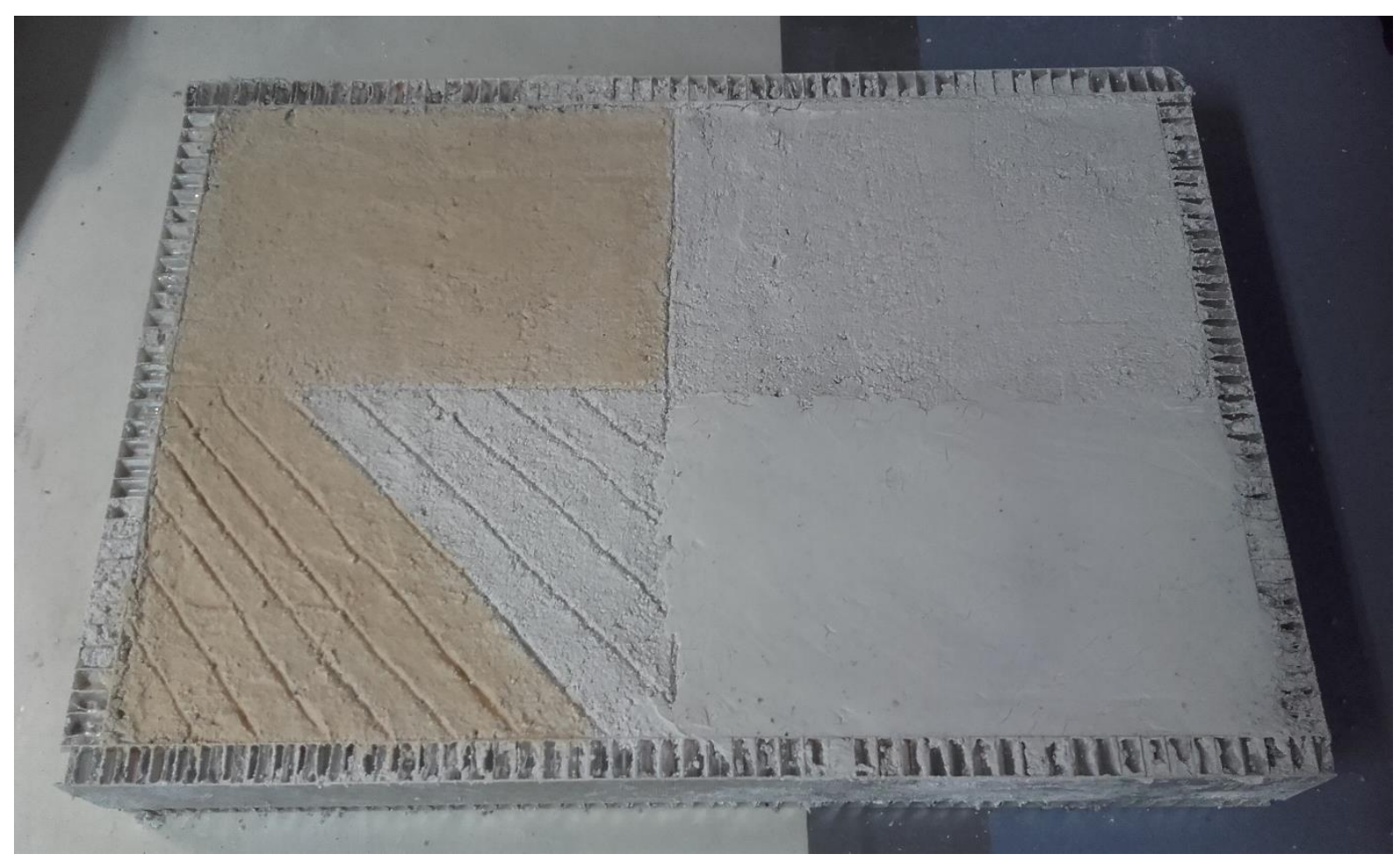

Fig. 1. The test substrate

\subsection{The test substrate}

As the subject of the investigations, a plastered test substrate was made in an aluminum frame. The material of the substrate was prepared from lime putty and quartz sand with a binder to aggregate ratio of 1:4. The plaster was applied in two layers. The surface finish of the substrate was prepared differently in the four quarters of the plaster (Fig 1.) to create altering optical environment for the expected efflorescence:

- upper-right corner in Fig 1. (upper-left corner in final position) - rendered surface

- lower-right corner in Fig 1. (upper-right corner in final position) - smoothed surface

- upper-left corner in Fig 1. (lower-left corner in final position) - rendered surface painted with yellow ochre

- lower-left corner in Fig 1. (lower-right corner in final position) - rendered, diagonally patterned surface partially painted with yellow ochre

Finally, we erected the frame, turned $90^{\circ}$ counter-clockwise, and placed it in front of the state-survey unit. 


\subsection{The state-survey unit}

\subsubsection{The used hardware}

The core of the hardware was a Raspberry Pi Zero W single-board computer, which was equipped with a Raspberry Pi V 2.1 camera module and a Grove Base Hat for the connection of the peripherals, like the sensors and the relays. The relative air humidity and the temperature are measured with an SHT31 Grove $\mathrm{I}^{2} \mathrm{C}$ temperature and humidity sensor, and an analog moisture sensor (Grove Moisture Sensor v1.4) which was placed $20 \mathrm{~mm}$ deep in the sample substrate. To ensure stable light conditions for the photos to be taken, an LED lamp was attached, that was supplied by electric power individually. Two relays were also used to switch a LED light and to switch off the power of the moisture sensor to reduce its corrosion during the time of the project. Finally, Raspbian Linux operation system was installed on the computer. The price of the survey unit was round $€ 130$, which is an acceptable price; however, we aimed to reduce the costs by testing possible alternative hardware.

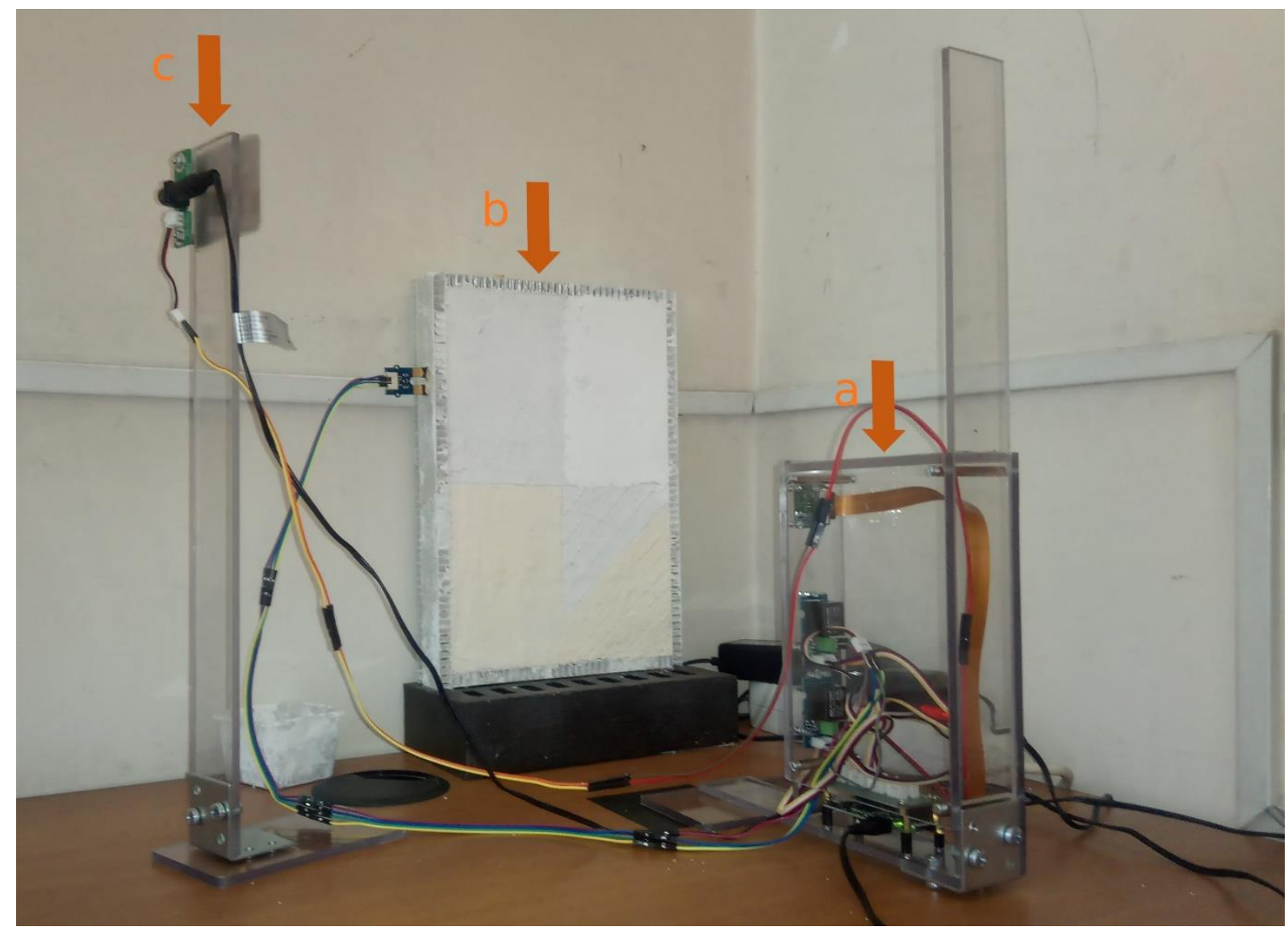

Fig. 2. The hardware - (a) state survey unit (b) test substrate (c) LED lamp

\subsubsection{The possible alternatives}

During the development time, we also took an attempt to create a smaller, cheaper, and more simple version of the state recording unit. The use of an ESP-32-CAM module with a DHT22 humidity and temperature sensor was considered as the first alternative. The unit was equipped with and USB lamp, which was switched from a 3.3V relay module. The price would be lower (round $€ 70$ ); however, this development board seemed to have a too modest capacity to run the camera, the relay, and the DHT module together.

We also built a unit with a Raspberry Pi Zero $W$ and Raspberry $V 2.1$ camera module again, equipped with a DHT22 temperature and humidity sensor, and a 3.3V relay, that was responsible for switching the USB led light. The light was fed from the same power supply as the Pi Zero this time. However, this second unit started to work only recently, so the experiences will be published later. 


\subsection{The performance of salt tests on the test sample}

In the frame of the sample substrate, $45 \mathrm{~mm}$ deep holes were bored sidewise, that were used to inject saline solutions and water into the substrate. Initially, we injected diluted sodium-chloride $(\mathrm{NaCl})$, and diluted calcium-nitrate $\left(\mathrm{Ca}\left(\mathrm{NO}_{3}\right)_{2}\right)$ several times in the system. Still, later we decided to use saturated sodiumchloride solution to increase the amount of the efflorescence.

Regularly, but on random days (altogether 58 times during the experiment), we also injected $6 \mathrm{ml}$ ordinary tap water to one or both top quarters of the substrate to have the salts transported towards the surface.

\subsection{The activity of the unit}

For taking photos, recording the measured values of the sensors, and controlling the relays of the system, a simple python code was written. The survey unit recorded the values of the sensors every second hour and took one photo every day. The data were recorded to a tab-separated text file; the photos were saved in a folder on the single-board computer. The system was running for preliminarily defined durations; however, after 30 to 45 days, we usually stopped and restarted it.

We used VCN Viewer application to control the unit, namely to manage the software and to up- and download data from the system. This remote control was really useful to reach the lab from a distance during the days of the COVID-19 epidemy in the spring of 2020.

We let the system run for 11 months from June 2019 to May 2020.

\section{Discussion}

\subsection{Observations}

\subsubsection{Efflorescence}

It was realized in the beginning already, that the effect of the diluted saline solutions would not turn out for a long time, neither in the case of sodium-chloride nor of calcium-nitrate. The reason is that the salt, which was stemming from the injections, did not make such amount of salt accumulation, which would cause efflorescence on the surface. Therefore, as far as we aimed a visible result, we decided to add a series of saturated saline solution injections, which were followed by efflorescence within a few days. This phenomenon can be observed in the photo series of Fig 3. With the help of the daily taken photos, we can follow the changes in the salt deposit on the surface of the sample substrate.

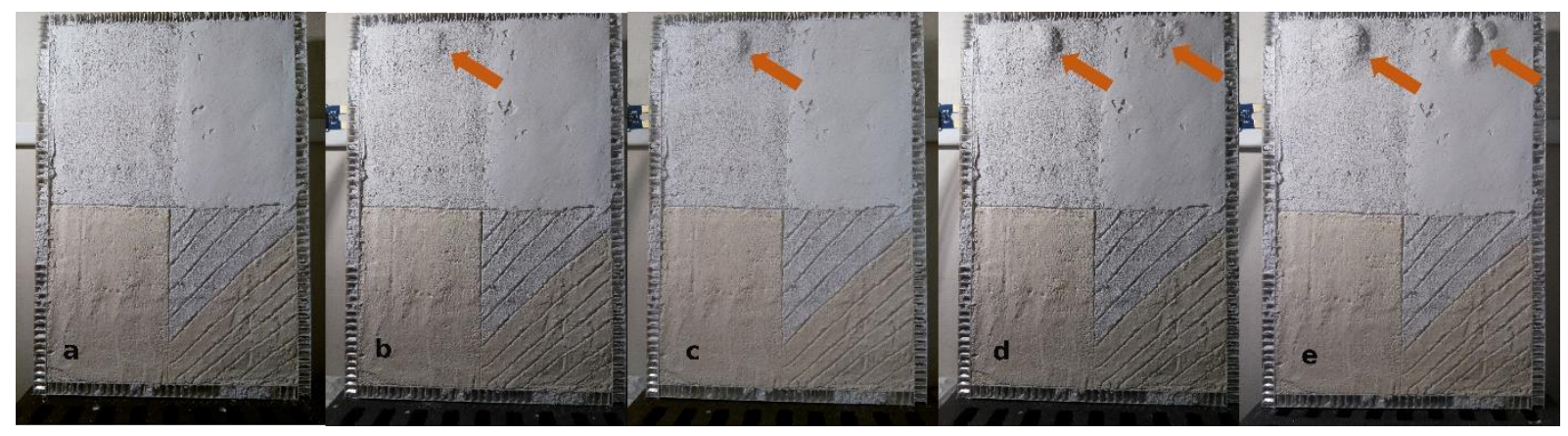

Fig. 3. Changing state of the plaster on some selected side-light pictures taken by the survey unit (a) June 2019; (b) September 2019; (c) December 2019; (d) Mach 2020; (e) May 2020

\subsubsection{The work of the sensors}

The SHT31 Grove $12 \mathrm{C}$ temperature and humidity sensor seemed to work well. The daily environmental circumstances were recorded properly without failure. The average values of the daily recorded data are demonstrated by the diagrams in Fig 4.a and Fig 4.b.

The applied contact moisture sensor, however, seemed to be idle, because of the low sensitivity to the moisture in the solid structure (Fig 4.c). While far from the injection (controlled with a Voltcraft MF-90 capacitive moisture meter unit) the moisture content of the sample substrate was approximately 29-33\%, close to the efflorescence (at the place where the built-in sensor was placed) the value vas $42-48 \%$, however, the sensor showed no relevant changes regarding the values. 
Testing the sensor independently from the system, even round 100\% percent of water/moisture content showed hardly any changes at its values, so this sensor type, which was developed to indicate soil moisture, was considered to be inadequate for our goals.

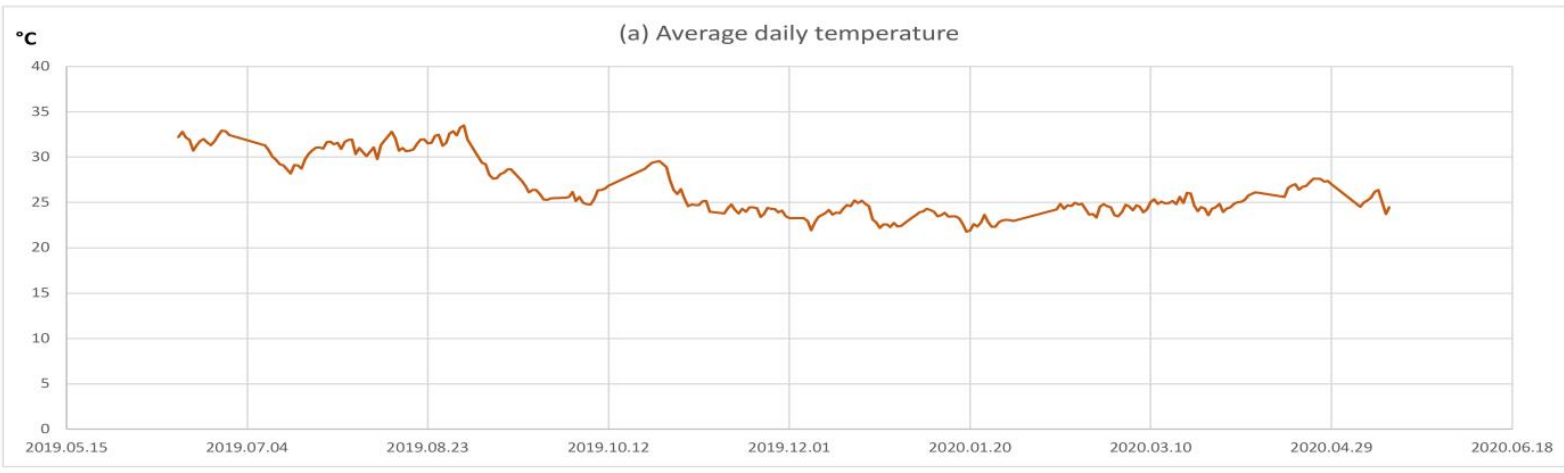

(b) Average daily relative humidity
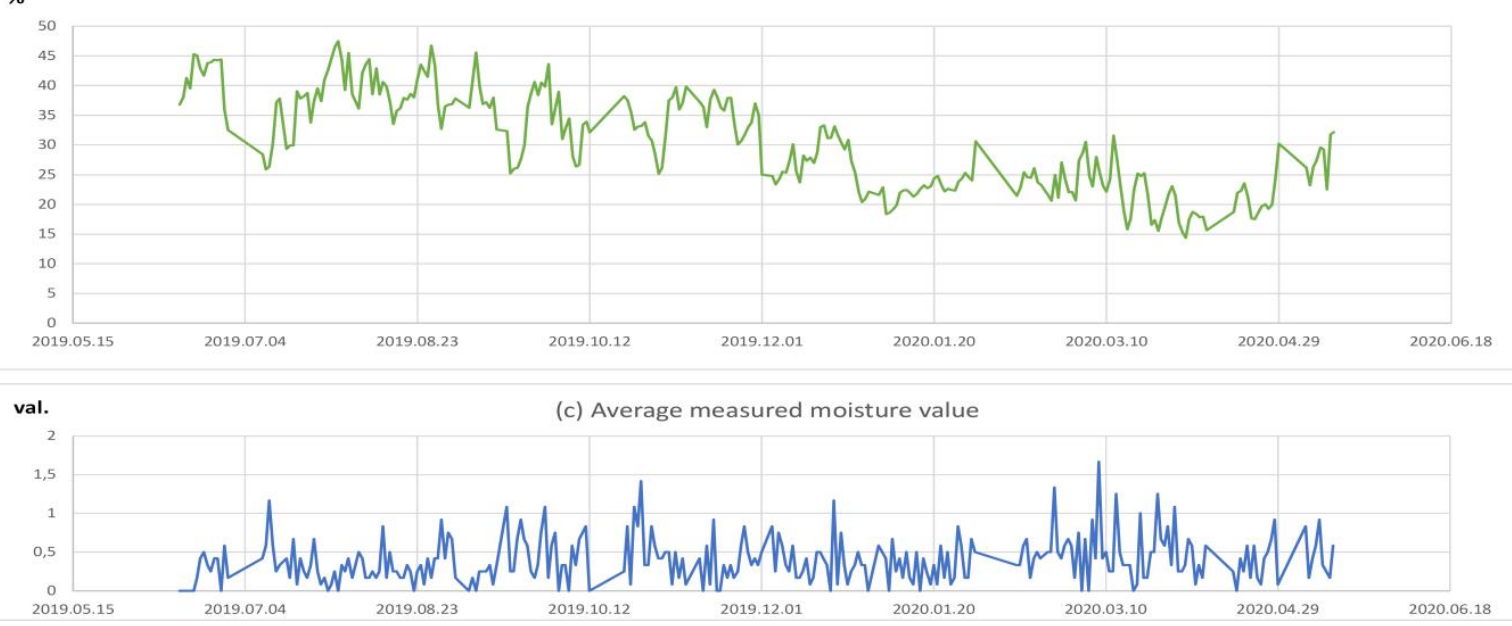

Fig. 4. Changes in the environmental circumstances (temperature, relative humidity) and the moisture

\section{Summary}

It can be stated that simple survey systems, like the one presented in this paper, are capable of recording the appearance of salts and the changes on plastered surfaces of historic masonry structures as a function of temperature and relative humidity. Salt damages triggered by climatic changes can thus be easily recorded as well as results may support conservators and maintainers to take appropriate actions to reduce the damage.

\section{Future plans}

As a next step, with the help of our set of state recording units, on-site surveys will be done at salt-laden historic masonries. The second alternative mentioned above seems to provide a feasible solution for our future plans.

\section{Acknowledgments}

The research reported in this paper has been supported by the National Research, Development, and Innovation Fund (TUDFO/51757/2019-ITM, Thematic Excellence Program).

\section{References}

[1] R. P.J. van Hees, S. Naldini, J. Delgado Rodrigues, "Plasters and renders for salt laden substrates", Construction and Building Materials, 23 (2009) 1714-1718. https://doi.org/10.1016/j.conbuildmat.2008.09.009

[2] Gabriele Grassegger, Hans-Jürgen Schwarz, "Salze und Salzschäden an Bauwerken" pp. 6-21 In: H-J. Schwarz, M. Steiger (ed.), "Salzschäden an Kulturgütern. Stand des Wissens und Forschungsdefizite." DBU Workshop, Osnabrück, February 2008.

[3] Heiner Siedel, "Zur Herkunft von Salzen an Bauwerken" pp. 22-29 In: H-J. Schwarz, M. Steiger (ed.), "Salzschäden an Kulturgütern. Stand des Wissens und Forschungsdefizite." DBU Workshop, Osnabrück, February 2008.

[4] P. Lopez-Arce, Ć E. Doehne, Ć J. Greenshields, Ć.D. Benavente, Ć D.: YoungTreatment of rising damp and salt decay: the historic masonry buildings of Adelaide, South Australia, Materials and Structures 42 (2009) 827-848. http://doi.org/10.1617/s11527-008-9427-1 
Proceedings of the Creative Construction e-Conference (2020) 002

Available online at e-2020.creative-construction-conference.com/proceedings/

[5] J. Ferdyn-Grygierek, J. Kaczmarczyk, M. Blaszczok, P. Lubina, P. Koper A. Bulinska, "Hygrothermal Risk in Museum Buildings Located in Moderate Climate" Energies, 13 (2020) 344. https://doi.org/10.3390/en13020344

[6] S. Brüggerhoff, G. Eggert, S. Simon, "Salze im Museum und in der Archäologie", In: H-J. Schwarz, M. Steiger (ed.), "Salzschäden an Kulturgütern. Stand des Wissens und Forschungsdefizite." DBU Workshop, Osnabrück, February 2008.

[7] Steffen Laue, Christine Bläuer, Erwin Stadlbauer, "Monitoring" pp.59-64 In: H-J. Schwarz, M. Steiger (ed.), "Salzschäden an Kulturgütern. Stand des Wissens und Forschungsdefizite." DBU Workshop, Osnabrück, February 2008.

[8] H. Juling, C. Franzen, "Schadensdiagnose", pp. 52-58. In: H-J. Schwarz, M. Steiger (ed.), "Salzschäden an Kulturgütern. Stand des Wissens und Forschungsdefizite." DBU Workshop, Osnabrück, February 2008.

[9] A. Perles, E. Pérez-Marín, R. Mercado, J. D. Segrelles, I. Blanquer, M. Zarzo, F. J. Garcia-Diego, "An energy-efficient internet of things (IoT) architecture for preventive conservation of cultural heritage," Future Generation Computer Systems 81 (2018) $566-581$. https://doi.org/10.1016/j.future.2017.06.030

[10 S. Madakam, R. Ramaswamy, S. Tripathi, "Internet of Things (IoT): A Literature Review. Journal of Computer and Communications", 3 (2015) 164-173. http://doi.org/10.4236/jcc.2015.35021

[11] K. Zehnder, O. Schoch, "Efflorescence of mirabilite, epsomite and gypsum traced by automated monitoring on-site", Journal of Cultural Heritage 10 (2009) 319-330. https://doi.org/10.1016/j.culher.2008.10.009

[12] S. Bruno, M. De Fino, F. Fatiguso, "Historic Building Information Modelling: performance assessment for diagnosis-aided information modelling and management," Automation in Construction 86 (2018) 256-276 https://doi.org/10.1016/j.autcon.2017.11.009 